EGU2020-8798

EGU General Assembly 2020

(c) Author(s) 2020. This work is distributed under

the Creative Commons Attribution 4.0 License.

\title{
The spatiotemporal dynamics of surface soil moisture within upland grassland ecosystems
}

\author{
Ethan Wallace and Nick Chappell \\ Lancaster Environment Centre, Lancaster University, Lancaster, United Kingdom of Great Britain and Northern Ireland \\ (e.wallace@lancaster.ac.uk)
}

Land conversion from semi-natural grassland to intensively managed pasture (for sheep, beef and dairy production) has altered the near-surface, soil moisture regime across much of the uplands of Europe. This widespread conversion has modified both the temporal distributions and spatial structure of surface volumetric wetness, thus affecting the incidence of flood-producing overland flow and resilience of the grasslands to drought stresses. In order to investigate these spatiotemporal dynamics, an intensive fieldwork campaign captured high-resolution $\left(1 \mathrm{~m}^{2}\right)$ surface volumetric wetness from a $1536 \mathrm{~m}^{2}$ paired-plot monitored over a year including both drought and fully saturated conditions. The measurements and combined statistical and geostatistical analyses form part of integrated studies into the hydrological effects of agricultural interventions to mitigate floods in the Cumbrian mountains of the UK.

The intensive monitoring highlighted significant temporal variations between land-uses. The pasture dried faster than the semi-natural grassland with the onset of a severe drought, but these effects were more than offset by the application of livestock slurry. This artificial wetting did however produce a more rapid build-up of moisture in the pasture with autumn storms. The large rain-event of Storm Diana (28-29 Nov 2019) did, however fully saturate both the pasture and seminatural grassland to generate visible saturation-excess overland flow. Seasonal changes in the spatial patterns of volumetric wetness were equally evident. The semi-natural grassland contained significantly larger variation within soil moisture statistical distributions and substantially larger coefficients of variation compared to the pasture throughout the study. Very weak spatial structure was observed within the semi-natural grassland. Conversely, a relatively strong spatial structure was observed within the pasture plot, which intensified with saturation, suggesting farming practices (ploughing, reseeding, artificial inputs, etc.) have removed natural soil moisture variability and encouraged moisture redistribution. A geostatistical model showed that the weak semi-natural grassland spatial structure remained relatively stationary, whereas the pasture showed extreme non-stationarity, with increasing saturation causing a gradual transition from an exponential to a gaussian geostatistical relationship.

The work highlights the complexity of spatiotemporal soil moisture dynamics taking place at the metre- to decimetre-scales through wetting-and-drying cycles and the strong impact of pasture management upon this. It justifies the need for both intensive soil moisture sampling at experimental sites, sampling across seasons, and the need for combined statistical and 
geostatistical analyses. Further such analyses in the uplands of Europe are needed if we are to better understand the effects of pastureland management on flood and drought hydrology, and to use this knowledge to mitigate our impacts on floods and droughts. 